\title{
Hendrik Dey, Elizabeth Fentress (eds.), Western monasticism ante litteram. The Spaces of Monastic Observance in the Late Antiquity and the Early Middle Ages
}

Turnhout, Brepols, 2011, 387 p.

Isabelle Jonveaux

\section{(2) OpenEdition}

Journals

\section{Édition électronique}

URL : http://journals.openedition.org/assr/26368

DOI : $10.4000 /$ assr.26368

ISSN : $1777-5825$

Éditeur

Éditions de l'EHESS

\section{Édition imprimée}

Date de publication : 31 décembre 2014

Pagination : 169

ISBN : 978-2-7132-2467-6

ISSN : 0335-5985

\section{Référence électronique}

Isabelle Jonveaux, « Hendrik Dey, Elizabeth Fentress (eds.), Western monasticism ante litteram. The Spaces of Monastic Observance in the Late Antiquity and the Early Middle Ages ", Archives de sciences sociales des religions [En ligne], 168 | 2014, mis en ligne le 09 avril 2015, consulté le 22 septembre 2020. URL : http://journals.openedition.org/assr/26368 ; DOI : https://doi.org/10.4000/assr.26368

Ce document a été généré automatiquement le 22 septembre 2020

(c) Archives de sciences sociales des religions 
Hendrik Dey, Elizabeth Fentress (eds.), Western monasticism ante litteram. The Spaces of Monastic Observance in the Late Antiquity and the Early Middle Ages

Turnhout, Brepols, 2011, 387 p.

Isabelle Jonveaux

\section{RÉFÉRENCE}

Hendrik Dey, Elizabeth Fentress (eds.), Western monasticism ante litteram. The Spaces of Monastic Observance in the Late Antiquity and the Early Middle Ages, Turnhout, Brepols, 2011, 387 p. 
Cet imposant ouvrage en papier épais offre un panorama surprenant du monachisme chrétien de l'Antiquité tardive au haut Moyen Âge. Issu d'une conférence organisée à l'American Academy de Rome en 2007, il recueille les travaux d'historiens et d'archéologues explorant le monachisme prébénédictin. Les photos et schémas des sites archéologiques permettent une compréhension plus vivante des lieux, proposant notamment des plans des grottes occupées par les moines. À la lecture de la diversité des phénomènes recensés, la conclusion qui s'impose, selon Elizabeth Fentress, auteur des remarques conclusives, est qu'il faut renoncer « au

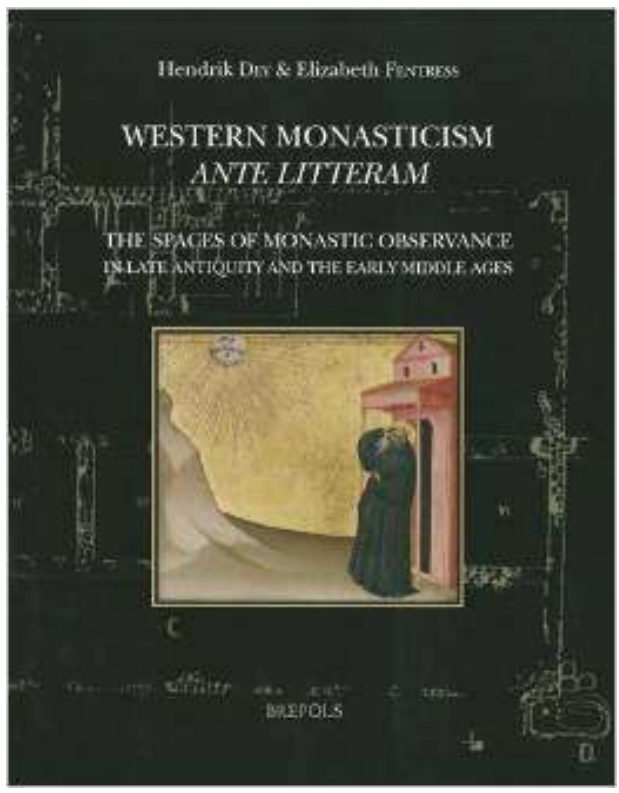
mythe de Benoît, le législateur génial et le père du monachisme européen » (p. 355, citant Prioco 1998, 749) ainsi qu'à l'idée d'une évolution linéaire depuis les ascètes du désert jusqu'au monachisme bénédictin.

2 Le monachisme prébénédictin est en effet extrêmement divers à tel point qu'il est difficile de donner une définition unifiée de la vie monastique. On trouve autant des regroupements d'ermites que des cénobites vivant en communautés, des villas reconverties en lieu de vie ascétique (voir le chapitre de Roberto Alciati) et des vierges demeurant dans leur famille (Lindsay Rudge), mais aussi des regroupements de moines vivant dans des cavernes ou des grottes creusées dans des parois rocheuses (Silviu Anghel). Avant l'unification du monachisme européen autour de la Règle de saint Benoît, notamment par l'intervention de Charlemagne, cette réalité apparaît donc assez hétéroclite. Selon Hendrik Dey, auteur de l'introduction, l'identité monastique était « $a$ separation that took many forms, among which spatial distance or seclusion was only one possible element $»$ (p. 29).

3 La problématique de cet ouvrage est en effet centrée sur la construction de l'espace ascétique, c'est-à-dire de l'espace dans lequel sera vécue l'ascèse. À cet égard, certains lieux, comme les cavernes ou le désert semblent porter a priori une plus grande charge ascétique que d'autres comme la ville ou la villa. Mais pour ces derniers, il s'agit justement d'aménager ou de réorganiser l'espace pour en faire un lieu de vie ascétique. Non seulement les formes de vie monastique sont diverses, mais aussi les lieux choisis pour la vivre, ce qui influence naturellement le quotidien de ces formes de retrait du monde. La distance du monachisme au monde n'est donc pas uniquement géographique et le monastère construit aussi une topographie céleste qui vise à réduire la distance entre le Royaume de Dieu et la terre.

4 Parmi les constantes qui peuvent malgré tout être discernées dans ces formes disparates de monachisme, la ségrégation hommes/femmes qui apparaît tout d'abord progressivement se retrouve ensuite dans la majorité des situations, y compris dans les basiliques elles-mêmes (Dossey). La question de l'identité sexuelle se pose en effet très tôt dans le monachisme, notamment du fait de la chasteté. Quand la réclusion apparaît, les femmes se trouvent la plupart du temps séparées des hommes et même dans les 
formes de vie religieuse accueillant des familles, hommes, femmes et enfants sont souvent séparés malgré des rencontres fréquentes. L'apparition de communautés de femmes semble faire naître le besoin de rédiger des règles spécifiquement féminines, mais malgré tout rédigées par des hommes. La règle de Césaire en est l'exemple principal. Il y prescrit la réclusion à vie des moniales qui doivent observer une clôture stricte et ne plus sortir du monastère une fois qu'elles y sont entrées. Les conséquences de cette clôture plus stricte imposée aux femmes se retrouvent encore dans le monachisme contemporain.

5 L'identité monastique des premiers siècles ne se construit pas nécessairement non plus autour d'une règle même si celle-ci, par nécessité et souvent en réponse à des demandes et des situations concrètes, prend de plus en plus d'importance. Et si le «Maître » et saint Benoît fustigent dans leurs Règles les « faux » moines qui vivent sans règles, cela signifie que la situation était courante. Ainsi que le souligne Albrecht Diem, la règle sert aussi souvent à prévenir les conflits.

6 Cet ouvrage aborde aussi dans deux chapitres (H. Kennedy et Y. Masarwa) un phénomène peu connu qui est celui des Ribat, lieux de retraite dans l'Islam du haut Moyen Âge qui ne sont pas sans présenter des analogies avec le monde monastique. Le comparatisme dans l'étude du monachisme est relativement rare, mais encore plus en ce qui concerne d'autres types de communalisation appartenant au monde islamique. Ces deux articles sont un point fort de ce recueil.

7 On soulignera enfin un index fort commode en fin d'ouvrage qui permet de retrouver les noms propres et thèmes essentiels. L'intérêt de ce livre est donc de présenter une approche renouvelée du monachisme prébénédictin en pointant la variété de ses formes et en obligeant ainsi le lecteur à se décentrer d'une approche linéaire et relativement homogène de l'histoire de la vie monastique. 